\title{
Article
}

\section{Stand for biomimetic swimming fins fatigue testing}

\author{
Radosław Kiciński ${ }^{1, *}$, Ewa Olewnik-Kruszkowska ${ }^{2}$ Bogdan Szturomski ${ }^{1}$ and Wojciech Jurczak ${ }^{1}$ \\ 1 Mechanical and Electrical Engineering Department, Polish Naval Academy, Śmidowicza 69 Street, 81-103, \\ Gdynia, Poland \\ 2 Chair of Physical Chemistry and Physiochemistry of Polymers, Faculty of Chemistry, Nicolaus Copernicus \\ University in Torun, Gagarin 7 Street, 87-200 Toruń, Poland \\ * Correspondence: $\underline{\text { r.kicinski@amw.gdynia.pl }}$
}

\begin{abstract}
The aim of the work is to present a newly developed stand and methodology of accelerated tests of fatigue strength of flexible propellers and fins. The paper presents the design and concepts of the measuring elements used in the research. Test methodology and water stressing were developed. The mechanical properties of the following materials were presented: Arnitel EL550 and QUEO 8230 with the addition of PP / EVA 50/50 (polypropylene / ethylene-vinyl acetate) in the proportion of 70/30 (QUEO 8230 / additive). The constructed test stand and a new method of fatigue testing of biomimetic fins made it possible to determine the number of fin movement cycles under a given load, which may facilitate the determination of a warranty for a newly introduced product. The current consumption by the fin drive and video monitoring allowed for the selection of the range of the number of movement cycles and the determination of the moment of fatigue cracks until the fin structure loses its capacity. During the analysis, the test results showed that the fins made of Arnitel EL-550 did not show changes in the measured values of the current and the force generated by the fin. For a fin made of QUEO 8230, at 35,000 cycles, there is a decrease in the current and force consumed, which indicates the initiation of fatigue damage to the fin. The performed tests can be the basis for the development of standards for the fatigue strength of flexible propellers.
\end{abstract}

Keywords: swimming fins testing, biomimetics, fatigue testing, thermoplastics, laboratory stand, accelerated fatigue testing

\section{Introduction}

Swimming fins are an indispensable element of every diver. They are used in many water sports such as snorkelling, recreational or deep diving. Various types of plastics or rubbers are often used to construct the fins. There are also many design solutions to improve the efficiency and comfort of use. There has been a significant interest in biomimetics in recent times [1-4]. Biomimetics is an interdisciplinary science dealing with the analysis of the structure and principles of living organisms' operation while adapting these principles to the construction and operation of technical devices $[5,6]$. The development of new solutions thanks to biometrics reduces randomness in scientific research and enables the easier generation of new solutions. One such solution is biomimetic swimming fins. Their innovation results from the design that mimics the movement of a fish's tail, increasing the fins' efficiency. This invention is already used by special maritime units, including divers from the Polish GROM commando unit. The EXOTECH company (Gdynia, Poland, https://foldingfins.com) which produces the abovementioned innovative fins, also undertook the production of recreational equipment based on similar assumptions and solutions. Tourists and diving enthusiasts can use such a fin. This solution is based on an invention covered by patent protection (No. PL403075) of the PPO. The innovation of the fins is the possibility of folding them like scissors, which significantly reduces the amount of space occupied. Moreover, thanks to 
the use of flexible film, the movement of the fin has been brought closer to the movement of the fish tail, which is both an element of biomimetics and an increase in the efficiency of the fins.

The shape and size of individual components of biomimetic fins, for strength reasons, are closely related to the type of construction material from which a given, specific component of the fin is made. The fin design includes using thermoplastic elastomers with properties similar to thermoplastics from the TPC group (Thermo Plastic Copolyester). The properties of biomimetic fins depend on the proper selection of the material, e.g. weight (mass) and volume or elasticity. The construction of a recreational biomimetic fin is shown in Figure 1.

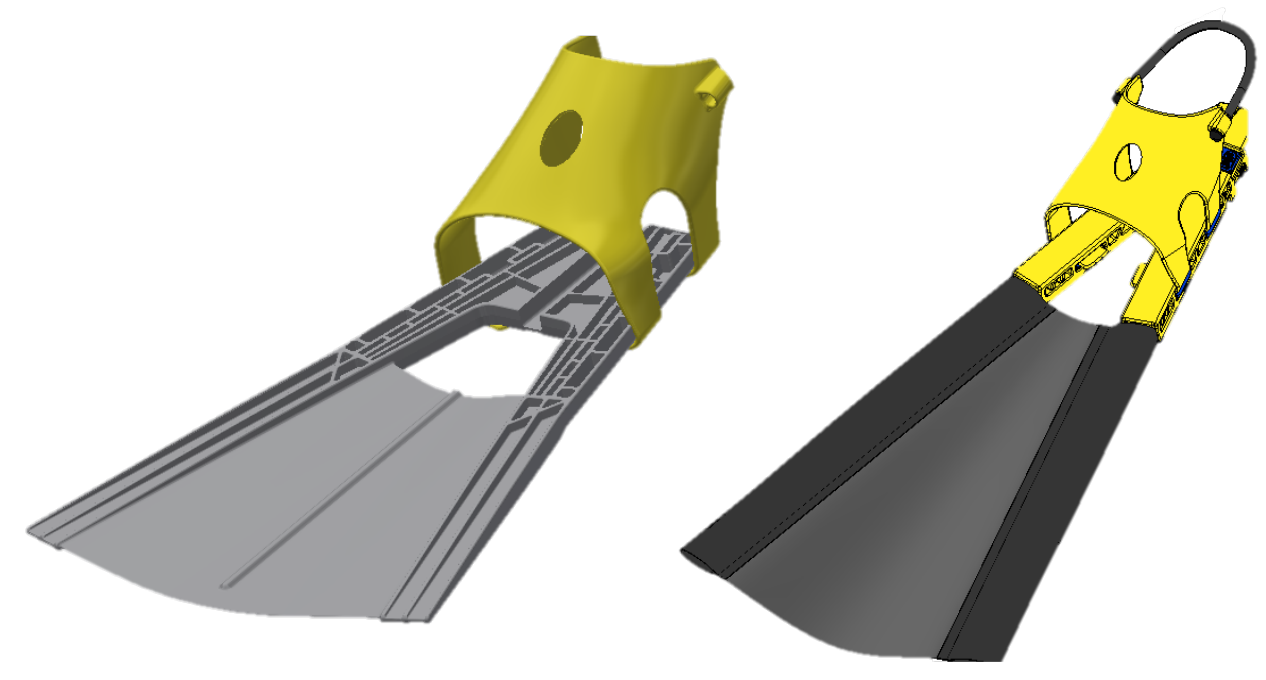

Figure 1. Biomimetic fins in the following versions: a) rescue, b) recreational

The main part introducing the element of innovation and biomimetics is the membrane. The movement of the fish tail inspired the concept of the construction of the entire fin. Analyzing the shape of the fish's tail, it can be concluded that it consists of two stiffeners and a thin film between them. The above phenomenon was used in the design and construction of the whole structure of the fins. Using the modal analysis, the planned movement of the fins in the water was presented in analogy to the movement of the fishtail (Figure 2). 


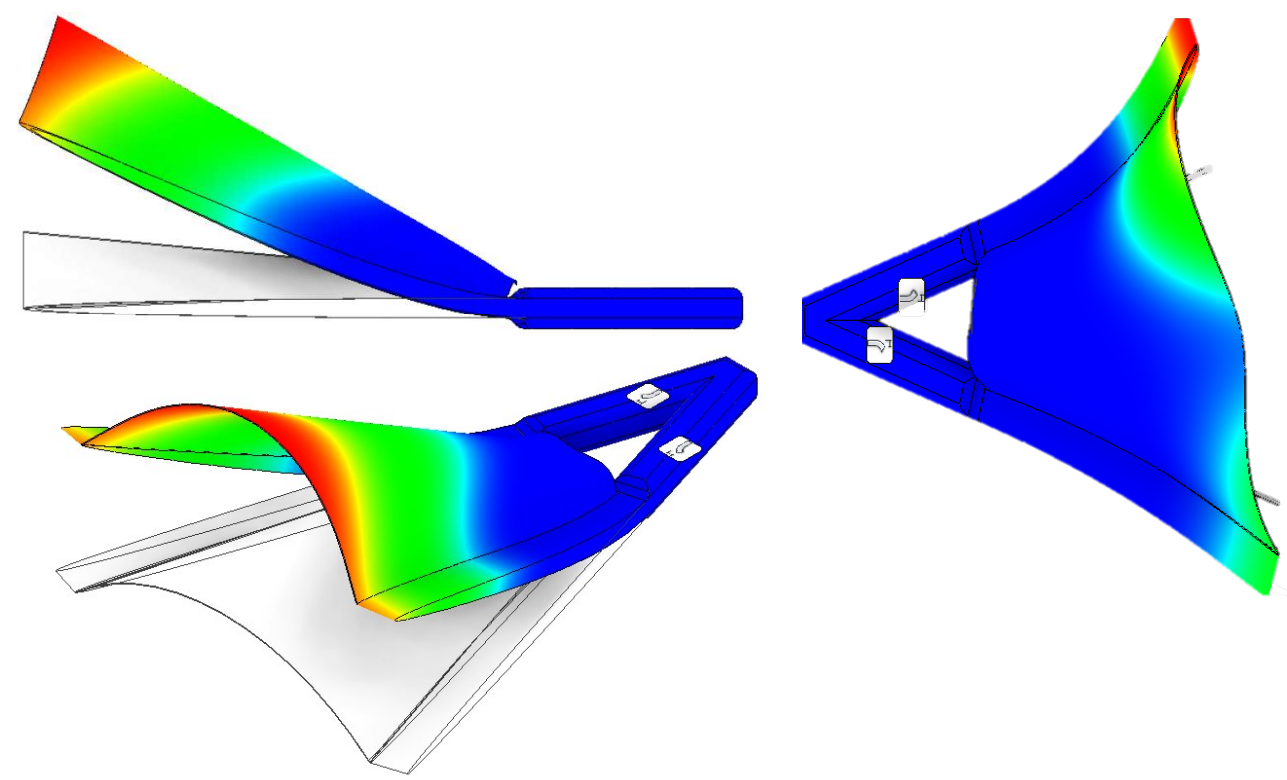

Figure 2. Selected deformation of the fins. The deformed fins resemble the movement of a fish's tail

The size of the membrane, its surface and thickness determine, for the same polymer, its elasticity, strength and durability. It also affects the efficiency and weight of the fin. Additionally, it is connected with other load-bearing elements, which, due to their functions, are made of different thermoplastic materials. In addition, the experience reported by divers using military fins shows that reinforcing strips are the most frequently damaged element. Thus, the fatigue strength of the fins and the durability are challenging to determine solely based on laboratory tests.

Both propellers and fins are devices on which human health and life rest. If the diver or a Biomimetic AUV (Autonomous Underwater Vehicle) [7] comes under water without efficient drive, there is a risk of loss of life or the vehicle. In order to carry out appropriate diagnostics of flexible components of flexible propellers and biomimetic fins, a stand for fatigue tests of such devices was developed. Due to the fact that currently there are no ready solutions to check the assumed fin strength, this manuscript presents a stand developed at the Polish Naval Academy for testing the fatigue strength of fins and biomimetic propellers. The stand was inspired by research work to measure the efficiency of the fins [8]. During research the problem of the assumed durability of the fins appeared.

In the case of polymeric materials, there are standards that allow to define the fatigue strength of a given material. However, this value depends on the type of injection and the forces acting on a given element. The determination of the fatigue strength of a material does not in any way say about the strength of the product. In this case, the product is new and the manufacturer would like to have a basis for providing an adequate warranty. Testing in real conditions would extend the process of introducing the product to the market, which would reduce its competitiveness. For example, when a manufacturer wants to test resistance to aging, samples are subjected to appropriate exposure to a UV lamp in accordance with PN-EN ISO 2440 [9]. This document specifies laboratory procedures simulating the effect of natural reactions, such as oxidation or hydrolysis under the influence of moisture, on flexible and rigid porous plastics. The physical properties of interest are measured before and after applying specific treatments. Taking into account the above assumptions, in the developed stand it was decided to simulate conditions similar to real ones in order to conduct accelerated fatigue tests of the final product. A literature analysis was carried out and no ready solution to the 
problem was found. Therefore, following the standards and publications relating to the testing of polymeric materials [10-14], a stand for fatigue testing of swimming equipment and flexible propellers was developed.

Moreover, the article proposes a methodology for conducting fatigue tests of swimming fins. The solution presented in the manuscript is also intended to encourage the development of this type of research, which may constitute the basis for the implementation of fatigue standards for flexible propellers.

\section{Materials and Methods}

EXOTECH made the tested fins in two variants of recreational and rescue fins.

Rescue fins are to be an additional equipment of escape and rescue suits used to save life at sea, which is why they are planned as a cheap and disposable product. Recreational fins are to be a civilized military product representing a new trend in water sports. Due to different purposes, the material from which they are made has other features. ARNITEL EL 550 (manufacturer: DSM) is selected for recreational fins due to durability reasons. It is a high-performance thermoplastic copolyester (TPC-ET) that offers a unique combination of flexibility, high-temperature resistance and strength, as well as excellent processing properties. This material has the following mechanical properties [15]:

- Shore hardness $\mathrm{D}=35$;

- Young's modulus $170 \mathrm{MPa}$;

- Tensile strength $32 \mathrm{MPa}$;

- Strain $640 \%$;

- Density $1200 \mathrm{~kg} / \mathrm{m}^{3}$.

For (disposable) rescue fins, the most crucial selection factor was the economy. Therefore, the octene- 1 plastomer based on ethylene, produced in the process of polymerization in a solution using a metallocene catalyst, under the trade name QUEO 8230 (manufacturer: Borealis) with the addition of PP / EVA 50/50 (polypropylene / ethylene-vinyl acetate) was selected to make the rescue fins (in the proportion of 70/30 (QUEO 8230 / additive). The catalogue of this material is characterized by the following mechanical properties [16]:

- Shore hardness $\mathrm{D}=<30$;

- Young's modulus $22 \mathrm{MPa}$;

- Tensile strength $7 \mathrm{MPa}$;

- Strain $980 \%$;

- Density $883 \mathrm{~kg} / \mathrm{m} 3$.

Methods

Methodology of the polymers mechanical properties testing

To find out the exact mechanical properties of the material, a static tensile test in accordance with PN-EN ISO 527-1 was carried out (

Figure 3). The test was performed quasi statically on the FU1000 testing machine. 

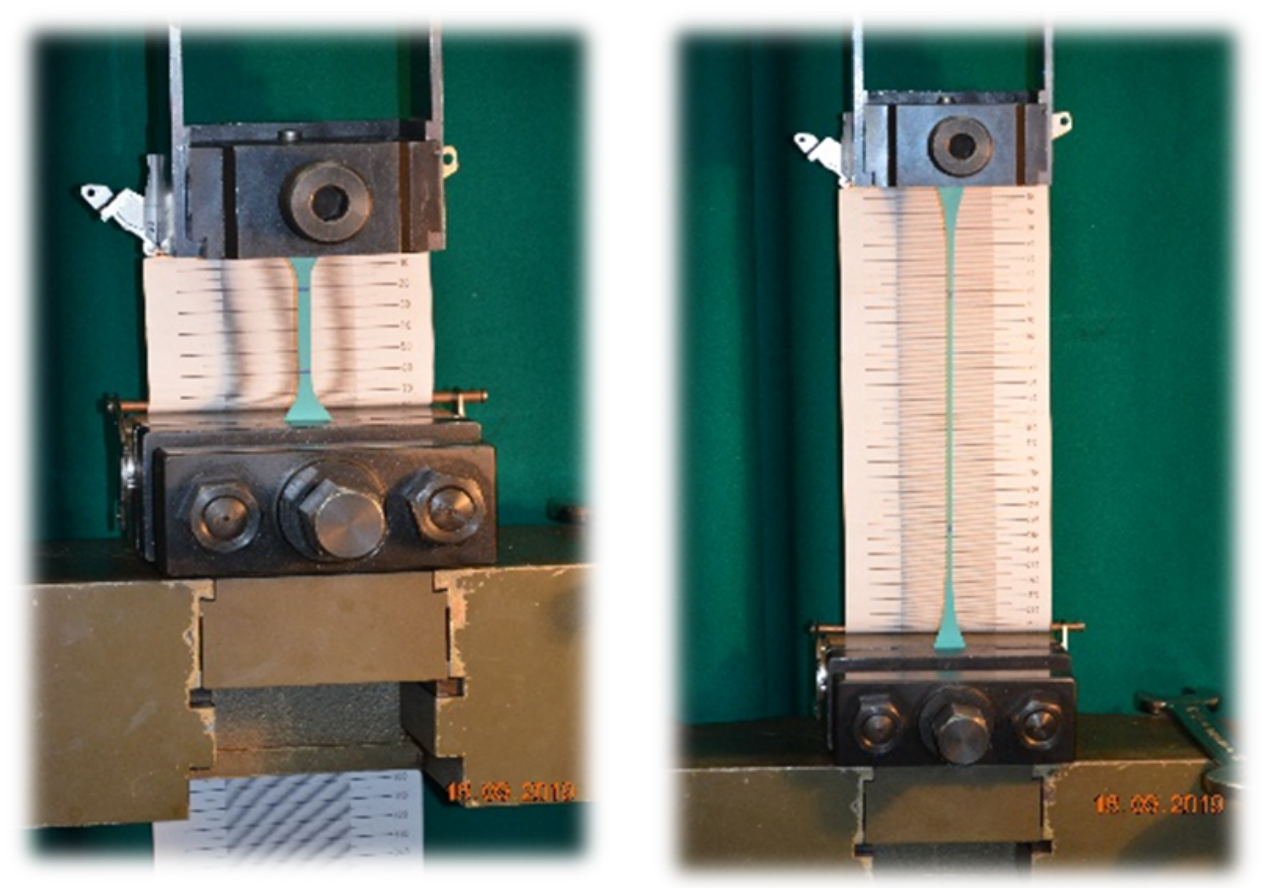

Figure 3. Testing the mechanical properties of Arnitel EL 550 on a laboratory stand

The experimental methods used to test the fatigue strength of polymers differ from each other. Pure shear load, tensile, or tear load are often used, the most common of which is the periodically alternating tensile test of a normalized sample [13]. This is because polymers have viscoelastic properties and poor thermal conductivity and are more sensitive to the conditions of their cyclic loading than metal [17]. Unlike metals and other alloys, polymers tend to soften under cyclic loading.

In the case of polymers, during loading, due to changes in the distance between polymer chains and rotations around chemical bonds, three types of deformation usually occur elastic, highly elastic and plastic, the value of which depends on the load. In rare cases, the polymers can remain stable at low strain, during which the polymer remains linearly elastic $[17,18]$. When analyzing the tensile curves of the tested polymers, it is difficult to correctly determine the linearly elastic sections, which makes the analysis much more difficult. Therefore, to assess the strength of the swimming fins, it was decided to build a test stand (Figure 4).

There are attempts in the literature to describe and analyze the movement of fins, but it is a very complex process $[19,20]$. However, there is no standard defining the fatigue testing of finished products such as swimming fins. Lack of the standard and other procedures for testing the properties of fins, including the fatigue strength of the fins, does not allow for a clear definition of the procedure for carrying out such a test. Therefore, based on the observation of the movement of the fins in the water, the fatigue cycle for the extreme load was determined. The test condition was established for the fin deflection with an angular range of $\pm 20^{\circ}$, a movement frequency of $0.5 \mathrm{~Hz}(\sim 30$ strokes per minute) and the assumption of a lifetime of at least 100,000 cycles.

The stand was designed to receive a relatively constant load resulting from the flow of water, and not to test the thrust and efficiency of the fins, which was performed on the stand presented here [8]. The stand described here can also be used to test the durability of other flexible propellers $[2,4]$. 
The designed and built stand allows for fatigue testing of practically any type of swimming fins in the angular range from $\pm 10^{\circ}$ to $\pm 30^{\circ}$ (with the possibility of step adjustment depending on the size of the fins). The fin fatigue strength test stand is located in a glazed pool, which allows observation of the fin movement during testing. The position consists of, among others from an electric motor with a $550 \mathrm{~W}$ inverter, a dynamometer with a measuring range of $\pm 200 \mathrm{~N}$, a digital multimeter with the possibility of continuous recording of measured values, a fin movement counter and a computer with software recording the force and current value (Figure 4, Figure 5).

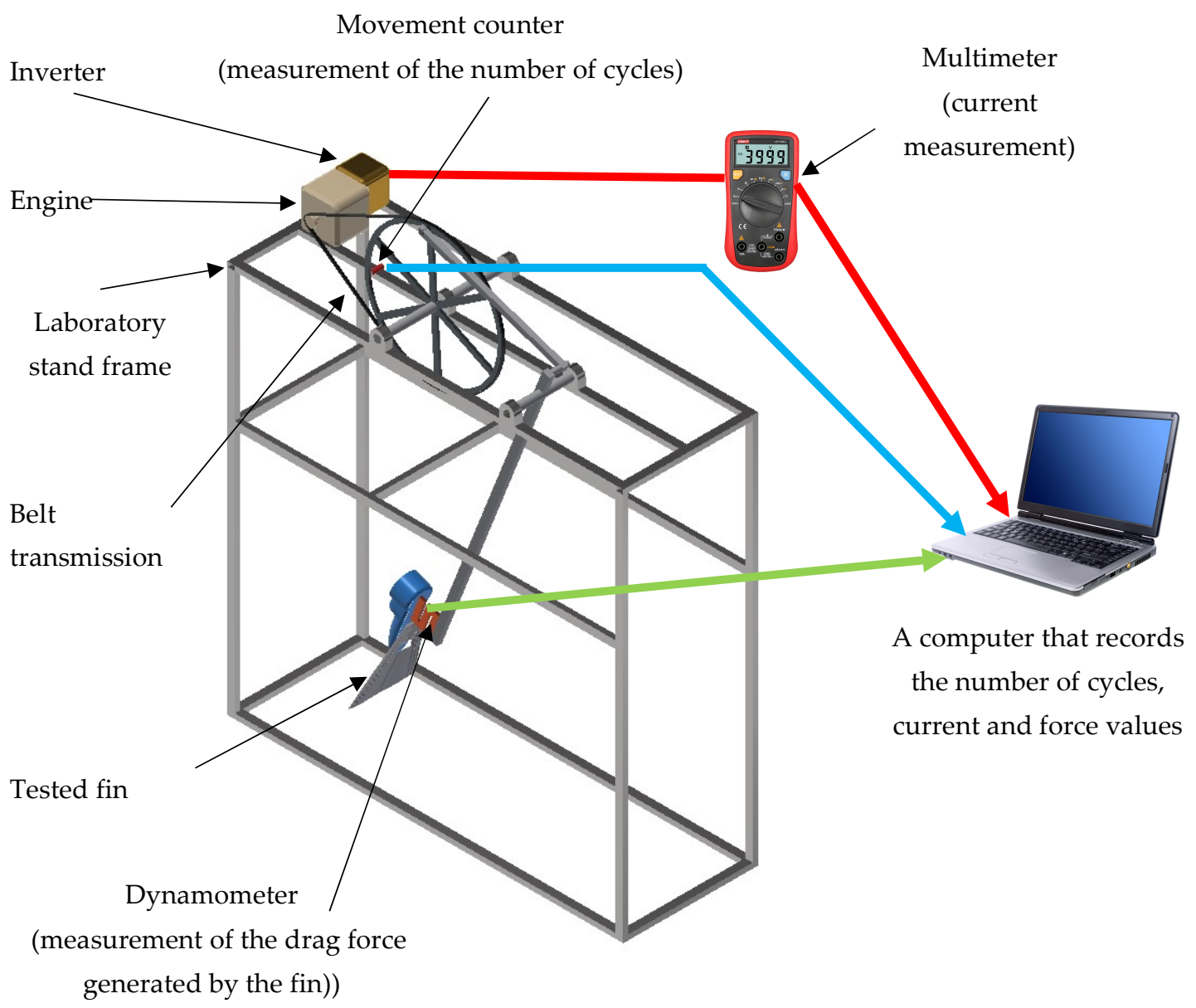

Figure 4. Stand for fatigue testing of biomimetic fins - functional diagram

Methodology of the fins fatigue strength of testing

The research began with attaching the fins to the handle (Figure 6.) The handle is connected to a dynamometer attached to the drive arm. The movement of the fins in the water creates a drag force which is recorded by the dynamometer. The dynamometer measures the drag force of the fin in the water. It is not the same as the thrust of the fin, which depends on its compliance and the skill of the diver. This is another reason why the movement of the fin is simplified and relates to the load on the material, not the diver. The crank was selected to obtain a fin deflection of $\pm 20^{\circ}$.

The device is connected to the power supply via a digital multimeter that allows for continuous recording of the electric current intensity.

Continuous digital recording of power and current consumption allows you to detect changes in the properties of the fins. A decrease in the current value or a change in 
the measured force during operation indicates the deterioration of the properties of the fins caused by material fatigue.

The first stage of the research was to establish reference values for the current and force generated by the machine without the fin attached. These values are necessary to show whether the fins were dragging in the water and generating thrust. After the reference values were measured, the fin testing was commenced. The engine speed and gear ratio allowed to obtain approximately 30 fin movements (cycles) per minute. Consequently, each type of fin (rescue, recreational) was attempted for around 50 hours. During the test, the current and the drag force generated by the fin were recorded. The measured results were then compared to the reference values of the machine itself (without the fin attached) to analyze the results.

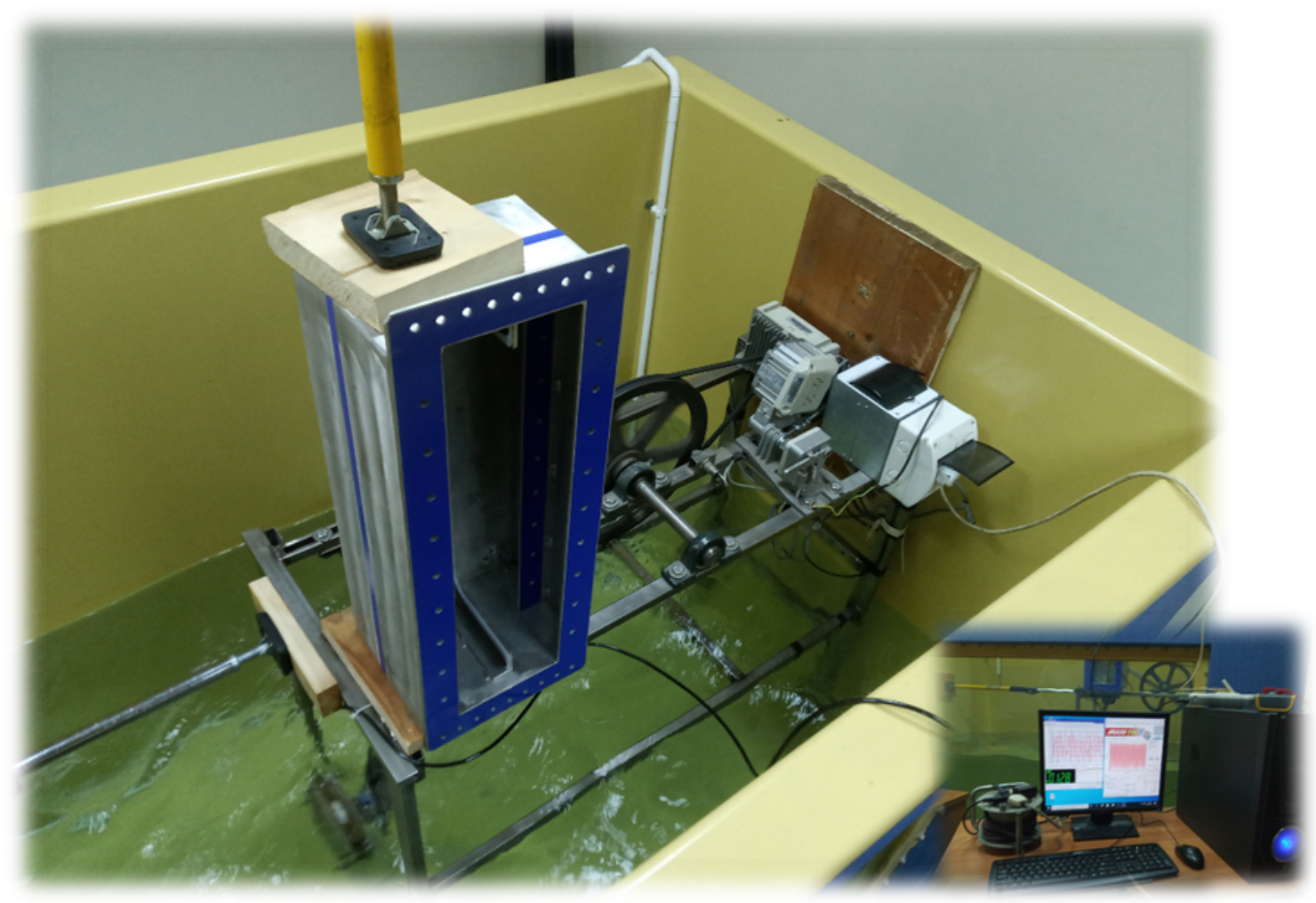

Figure 5. Fin fatigue test stand during measurements 


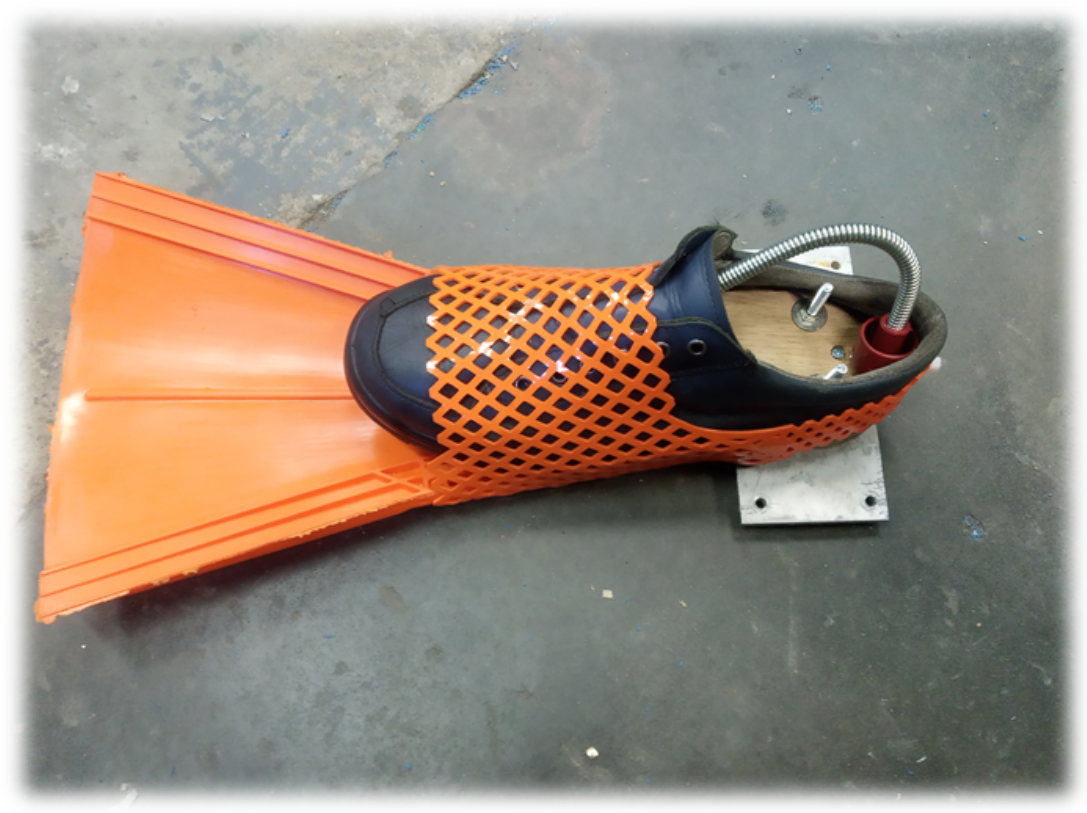

Figure 6. Holder for attaching the fins

As part of the fatigue tests, the fins made of, among others, materials with the following trade names were also tested (Figure 7):

- Santoprene 12350W175 (Thermoplastic Vulcanizate, manufacturer: PROplast);

- Isothane 5055D (Thermoplastic polyurethane, manufacturer: Great Eastern Resins Industrial).

Regarding the above materials, only fatigue analyses of the finished product were carried out without considering the mechanical properties.
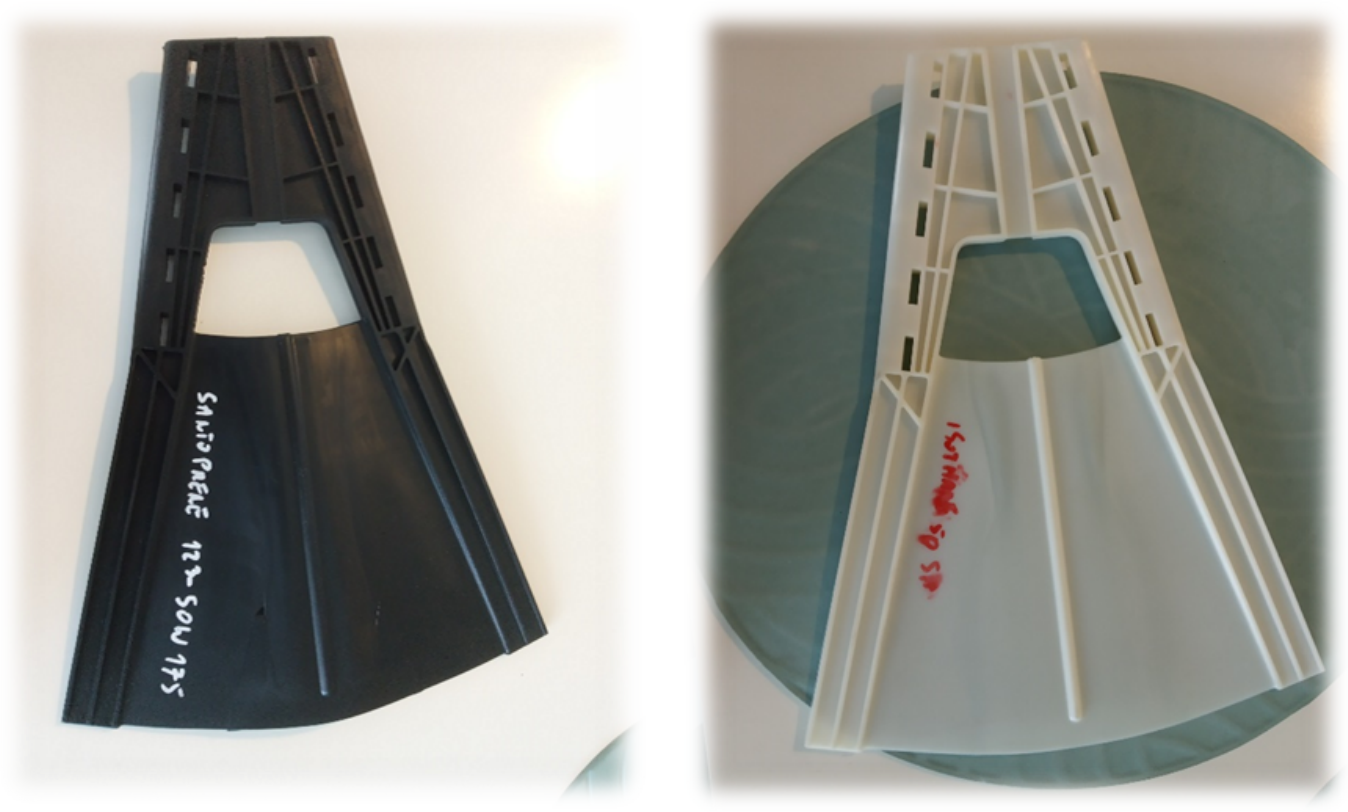

Figure 7. Fins made of Santoprene 12350W175 (left) and Isothane 5055D (right) 


\section{Results}

\section{Mechanical properties}

Based on the static tensile test results, strain-strain diagrams were prepared for materials typed as the structural elements of the fins. In the case of the ARNITEL EL-550 material, the results are in line with the catalogue data [15], while for QUEO 8230 [16], the results were divergent in terms of deformation. Due to the addition of PP / EVA, the deformation of the plastomer decreased to about $140 \%$, while the catalogue value was $980 \%$.

The addition of PP / EVA increased the structure's stiffness, which is a deliberate procedure due to the functionality of the fin. Too little stiffness of the material reduces the thrust force of the fin, which harms its efficiency. The stress-strain curves for the tested materials are presented in Figure 8.

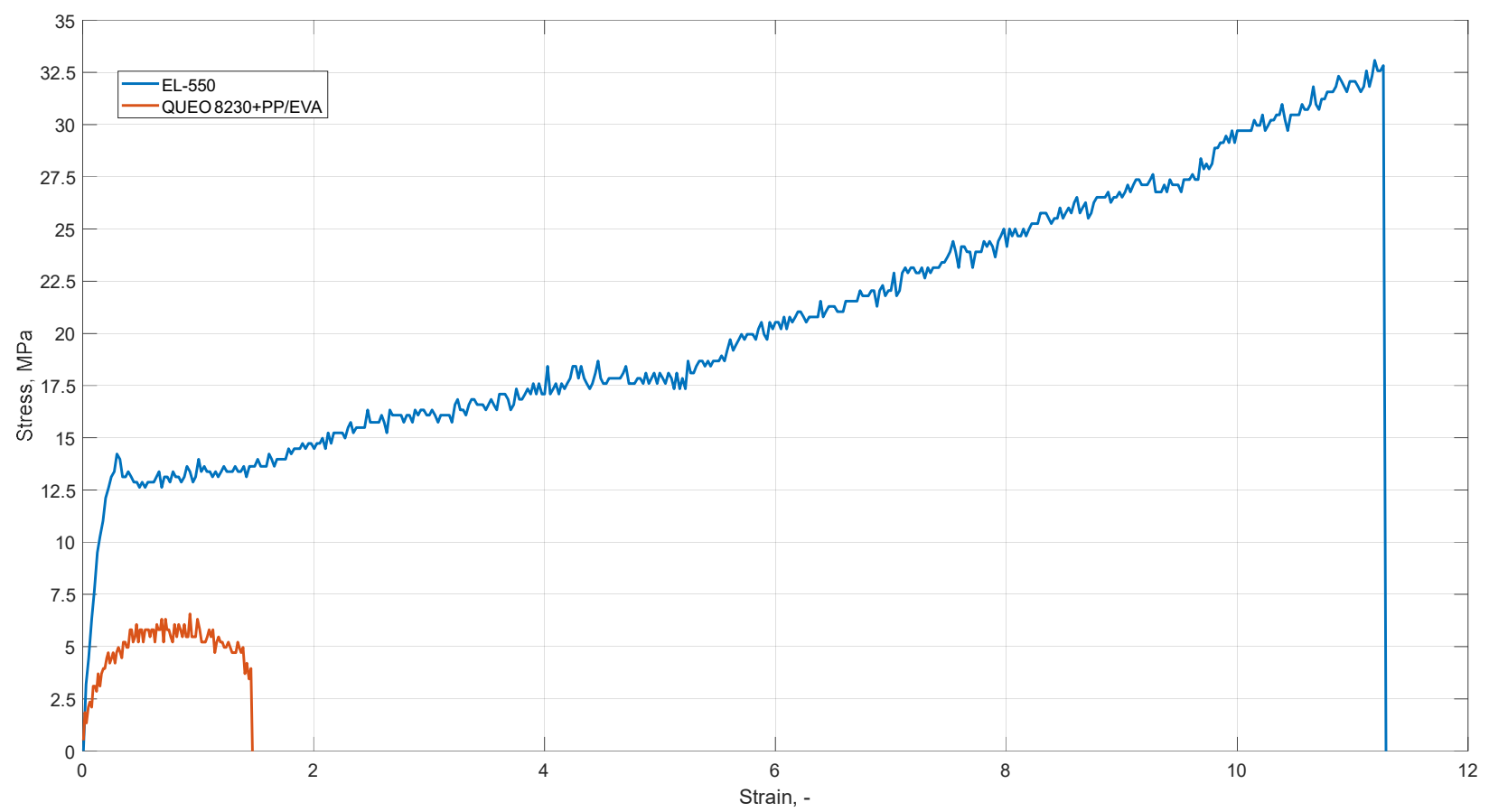

Figure 8. Stress-strain diagrams of fins materials

Determining the basic mechanical properties of polymers is standardized and poses no engineering challenge. A more complex issue is the determination of their fatigue strength. The fatigue life of a polymer is influenced by many factors, including the temperature of use, oxidation, and the degree of polymer crystallization. For this reason, the need to study and predict the properties of polymers in various environments becomes of utmost importance [21].

Fatigue tests of rescue fins made of QUEO 8230 plastomer.

A rescue fin made of QUEO 8230 plastomer was installed in the holder, and the test was started (Figure 9). The fin made 100,000 movements in the water, during which the current and the drag force generated by the fin were recorded (Figure 10). The test results are shown in photos (Figure 11) and in diagrams (Figure 12). 

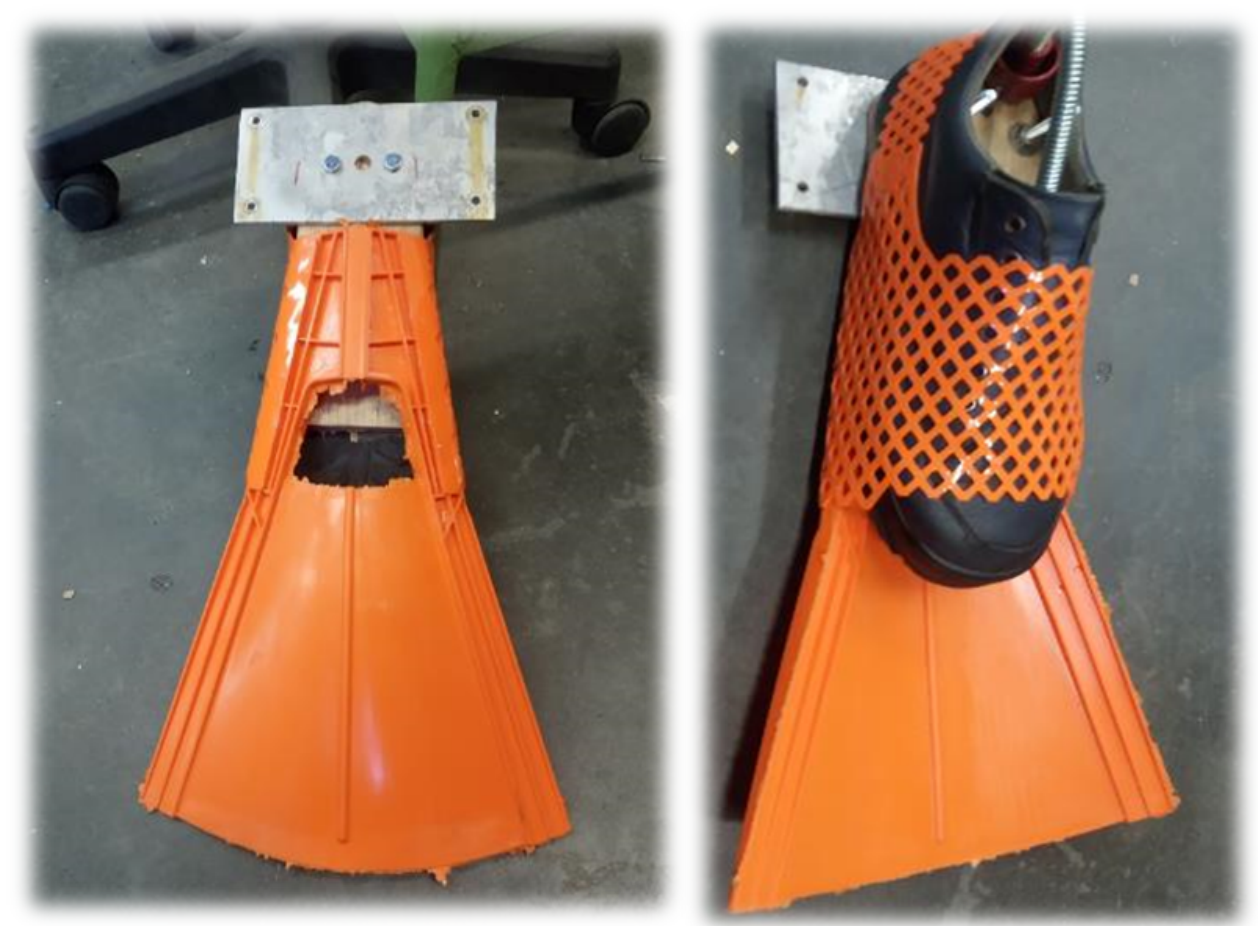

Figure 9. Rescue fin made of QUEO 8230 plastomer before testing

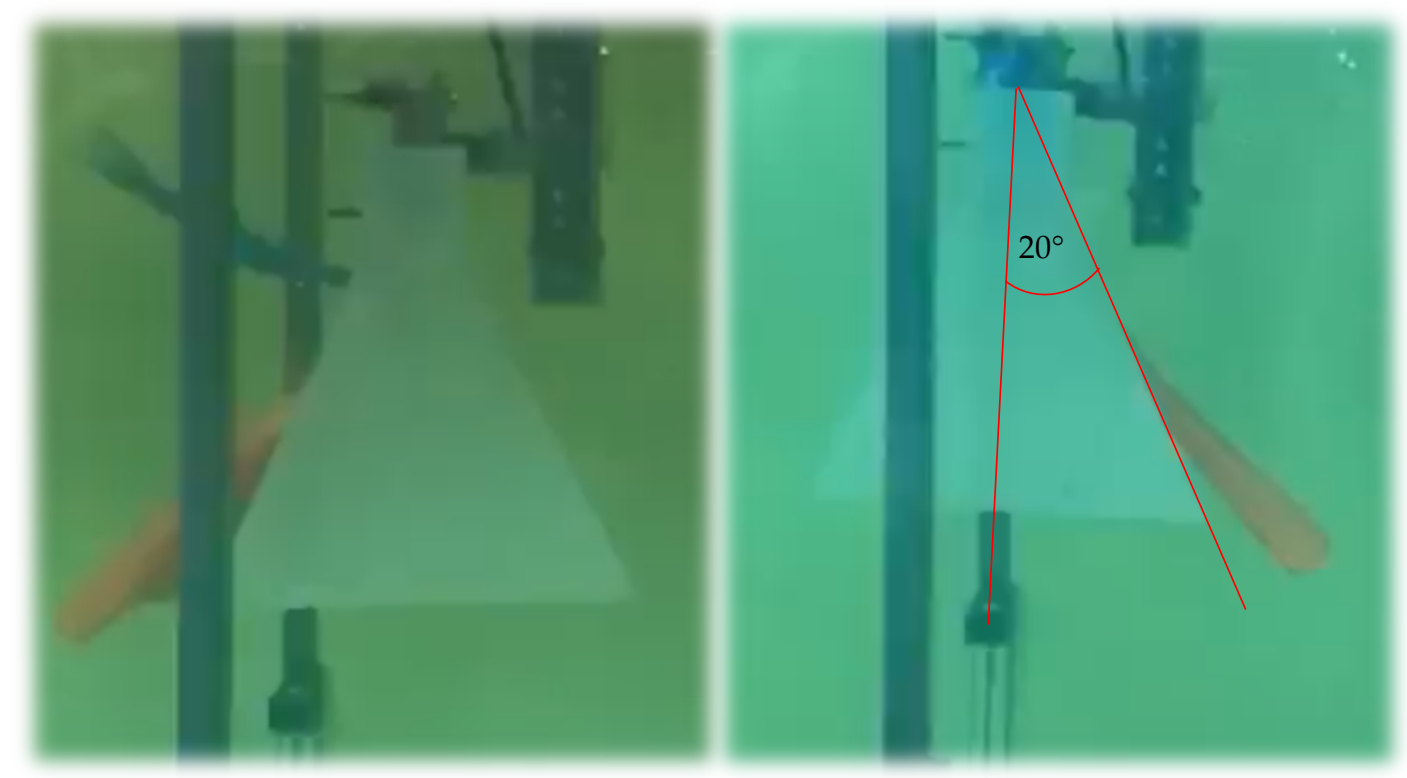

Figure 10. Rescue fin made of QUEO 8230 plastomer during testing 


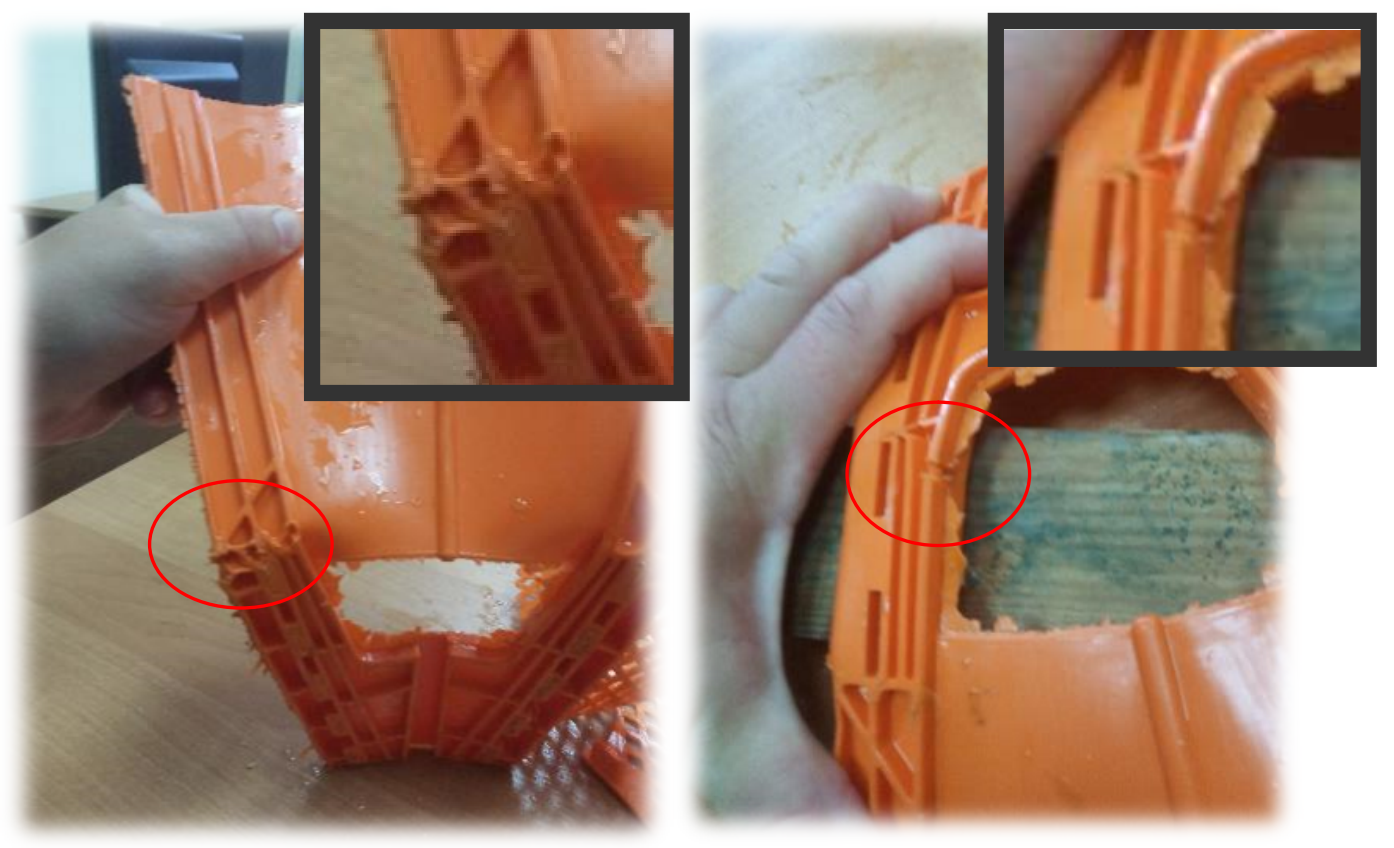

Figure 11. Rescue fin made of QUEO 8230 plastomer after fatigue testing 
a)

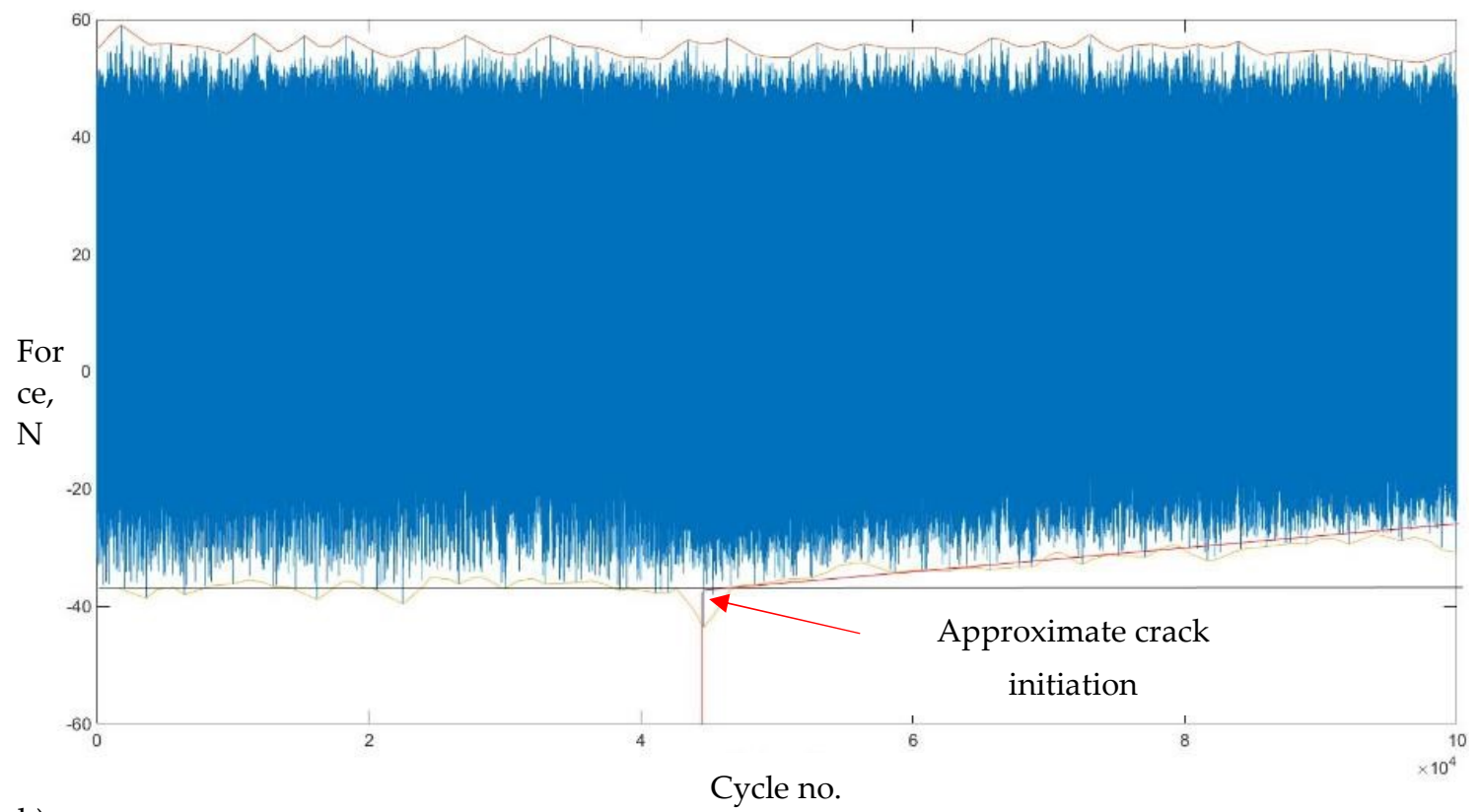

b)

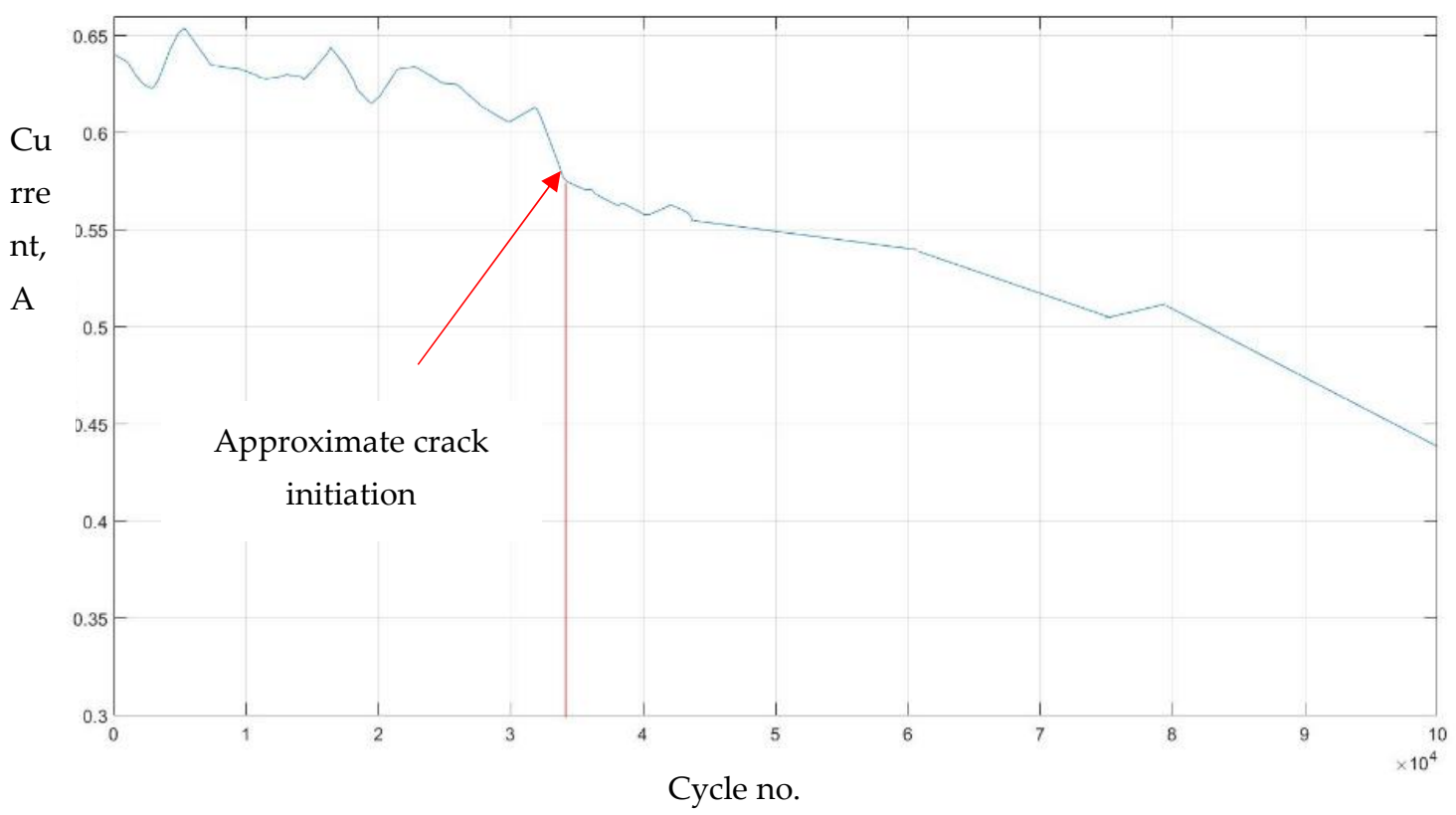

Figure 12. Values of force (a) and current envelope (b) measured during the fatigue test of a rescue fin made of QUEO 8230 plastomer. Visible differences result from two independent measurement systems. A lower value should be taken as the initiation of fatigue.

Fatigue testing of rescue fins made of Arnitel EL - 550

The fatigue tests of the Arnitel EL - 550 rescue fins began with the measurement of the reference values of the current consumed and the drag force of the machine without the fin installed. Then an Arnitel EL - 550 thermoplastic rescue fin was installed in the holder, and the trial was started. The fin made 100,000 movements in the water, during which the current intensity and the drag force generated by the fin were recorded. The results of the fin tests are presented in charts and photos (Figure 13, Figure 14.) 

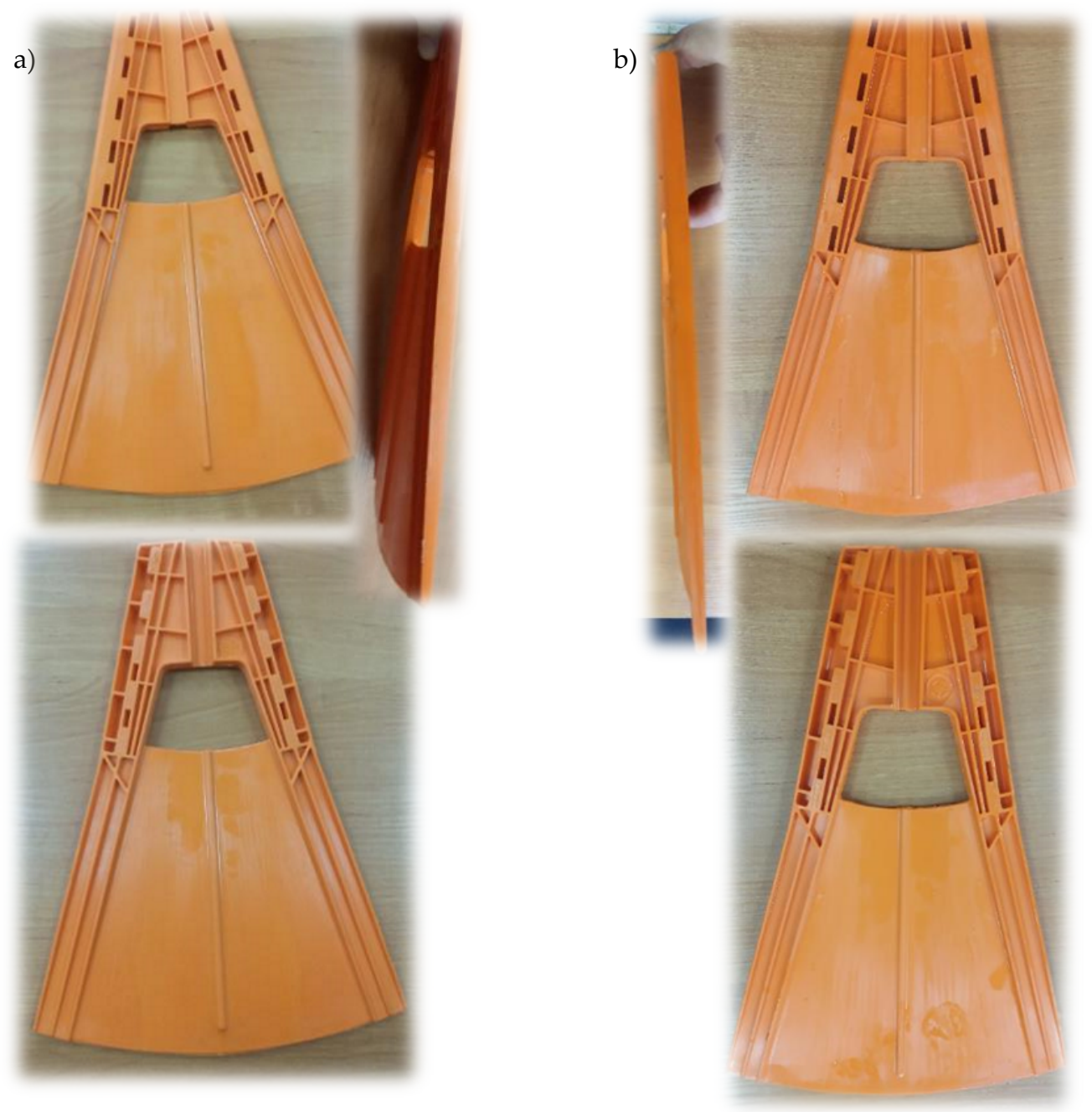

Figure 13. Rescue fin made of Arnitel EL - 550 thermoplastic before testing (a), after testing (b) 
a)

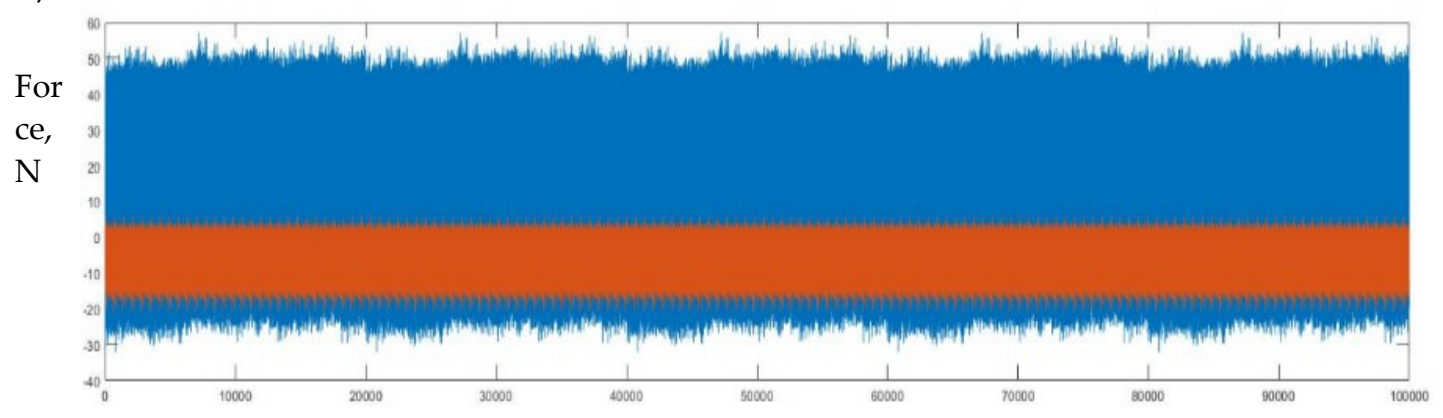

b)

Cycle no.

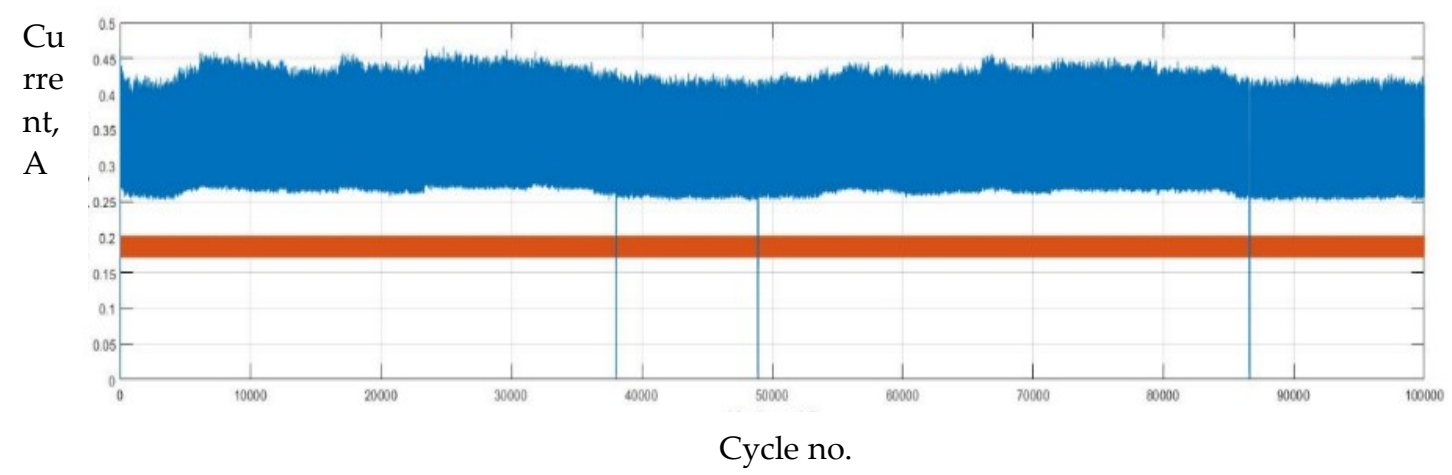

Figure 14. Values of force (a) and current (b) measured during fatigue analysis of a rescue fin made of Arnitel EL - 550 thermoplastic (the machine resistance is marked in orange)

\section{Discussion}

Based on the fin results made with QUEO 8230, it can be seen that the fatigue failure of the tested fin started at about 40,000 cycles, which is illustrated by the decrease in the value of the measured force (Figure $12 \mathrm{a}$ ). The process then proceeded for another 60,000 cycles. Based on the graph showing the dependence of the change in the current intensity value on the number of cycles (Figure $12 \mathrm{~b}$ ), a significant decrease in the value of the current intensity can be noticed at about 35,000 cycles. Combining these parameters as a function of the number of cycles makes it possible to determine that in a fin made of QUEO 8230 material, the destruction is initiated at 35,000-40,000 cycles. The structure, however, does not lose its complete continuity at 100,000 (Figure 11), which allows the conclusion that the functionality of the tested fin is maintained (increasing the thrust force generated by diver). Evident fatigue damage occurs in the plane of stiffness change (at reinforcements) and in the area of the fin attachment.

When analyzing the results relating to the rescue fin made of Arnitel EL 550 (Figure 13, Figure 14), it can be concluded that the fin was not visibly damaged during the assumed working time. This is also confirmed by the analysis of the graphs of changes in force and current intensity. Visible small changes in the current intensity and force value result from changes in the normal environmental conditions, such as, e.g. temperature, etc., current, drag force (Figure 14), which leads to the conclusion that it can withstand a fatigue load of 100,000 cycles.

Fatigue tests of fins made of materials with the following trade names were also carried out:

- Santoprene 12350W175 (Thermoplastic Vulcanizate, manufacturer: PROplast); 
- Isothane 5055D (Thermoplastic polyurethane, manufacturer: Great Eastern Resins Industrial).

During the fatigue test, these fins did not significantly change the tested parameters (the value of the generated force and the current intensity). Therefore it was decided to omit them in the following descriptions.

They were presented to show the differences in the value of the current intensity depending on the material used. The data in Figure 15 shows that, depending on the material used, the current was consumed with the same fin structure. This is due to the different susceptibility of each of the materials. Moreover, based on the above data, it was found that, except for the QUEO 8230 material, the current consumption for the remaining materials was constant, which proves the lack of fatigue failure initiation for the fins made of Arnitel, Santoprene and Isothane.

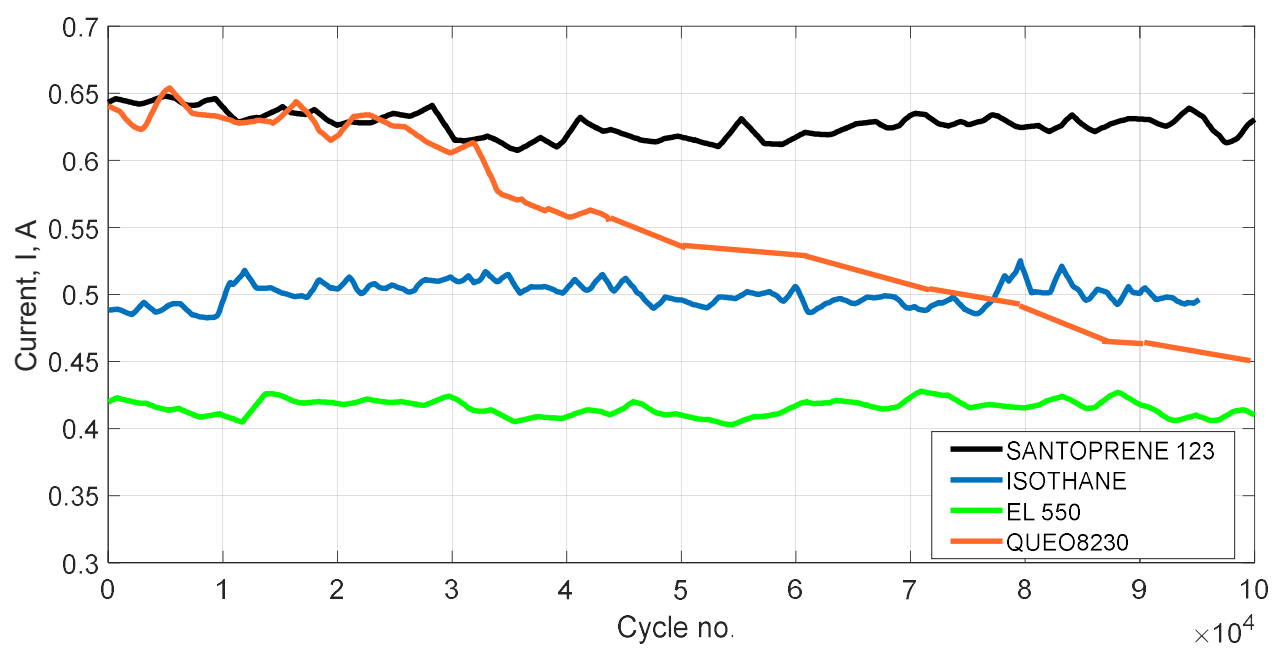

Figure 15. Comparison of the current consumption by the test stand depending on the type of material from which the tested fins were made

\section{Conclusions}

Based on the conducted research, it was found that the developed methodology and test stand are optimal for determining the fatigue strength of swimming sports equipment, including biomimetic fins. Moreover, it allows fatigue measurements of membranes, the strength of which is difficult to determine due to the ignorance of the load direction. Registering the drag force of the fin and the current allows for the indication of the number of cycles at which the fatigue failure initiation takes place, so that the durability of the fins can be predetermined.

The article presents the research results for two types of rescue fins made of QUEO 8230 and Arnitel EL - 550. This way of showing the results is deliberate so as not to burden the image of the fin producer. In the target product, the company considered the research results, optimizing the economical variant of the material used. The result was a marked improvement in the fatigue strength of the fins, as shown in the figures (Figure 11, Figure 13). Thanks to the developed stand, it was decided to change the material and slightly redesign the fin reinforcements. This approach to research prevented the release of the defective product on the market and allowed for a preliminary identification of operational problems resulting from the defective design. This clearly impacts the product quality policy and should be an indispensable element of quality control.

The obtained results allow for a preliminary determination of the power generated by a given fin. In the case of a rescue fin made of QUEO 8230, the current consumption 
(after subtracting the reference value of the machine resistance) varied from about $0.24 \mathrm{~A}$ to 0.04 A (Figure 12b). In the case of a fin made of Arnitel EL - 550, the current consumption oscillated around 0.23 A (Figure 14b). Based on the measured current values, it can be concluded that at a voltage of $230 \mathrm{~V}$, the investigated rescue fin generates about $55 \mathrm{~W}$ of power. Due to the local loss of structure continuity caused by fatigue failure in the case of a fin made of QUEO 8230, the generated power drops to about $10 \mathrm{~W}$, which decreases the fins' efficiency. However, it should be noted that the obtained results are only a preliminary determination of the power generated by the tested fins.

Author Contributions: Conceptualization, R.K.; methodology, R.K.; software, B.S, R.K.; validation, R.K..; formal analysis, B.S, E.O.; investigation, R.K..; resources, R.K..; data curation, R.K..; writing - original draft preparation, R.K..; writing - review and editing, R.K. and E.O.; visualization, X.X.; supervision, J.W..; project administration, R.K..; funding acquisition, J.W. B.S. All authors have read and agreed to the published version of the manuscript.

Funding: This research received no external funding.

Institutional Review Board Statement: Not applicable.

Informed Consent Statement: Not applicable

Conflicts of Interest: The authors declare no conflict of interest. EXOTECH has been informed about this publication and has consented to it.

\section{References}

1. Roth, R.R. The Foundation of Bionics. Perspectives in Biology and Medicine 1983, 26, 229-242, doi:10.1353/pbm.1983.0005.

2. Piskur, P.; Szymak, P.; Przybylski, M.; Naus, K.; Jaskólski, K.; Żokowski, M. Innovative Energy-Saving Propulsion System for Low-Speed Biomimetic Underwater Vehicles. Energies 2021, 14, 8418, doi:10.3390/en14248418.

3. Łagód, G.; Duda, S.M.; Majerek, D.; Szutt, A.; Dołhańczuk-Śródka, A. Application of Electronic Nose for Evaluation of Wastewater Treatment Process Effects at Full-Scale WWTP. Processes 2019, 7, 251, doi:10.3390/pr7050251.

4. Piskur, P.; Szymak, P.; Kitowski, Z.; Flis, L. Influence of Fin's Material Capabilities on the Propulsion System of Biomimetic Underwater Vehicle. Polish Maritime Research 2020, 27, 179-185, doi:10.2478/pomr-2020-0078.

5. Tang, X.; Staack, D. Bioinspired Mechanical Device Generates Plasma in Water via Cavitation. Sci. Adv. 2019, 5, eaau7765, doi:10.1126/sciadv.aau7765.

6. Odum, H.T.; Odum, H.T. Ecological and General Systems: An Introduction to Systems Ecology; Rev. ed.; University Press of Colorado: Niwot, Colo, 1994; ISBN 978-0-87081-320-7.

7. Praczyk, T. Correction of Navigational Information Supplied to Biomimetic Autonomous Underwater Vehicle. Polish Maritime Research 2018, 25, 13-23, doi:10.2478/pomr-2018-0002.

8. Grządziela, A.; Kluczyk, M.; Batur, T. The Stand For Fin Drives Energy Testing. ped 2021, 93, 250-262, doi:10.53656/ped216s.22sta.

9. Polski Komitet Normalizacyjny PN-EN ISO 2440: Flexible and rigid porous plastics: accelerated aging tests; Polski Komitet Normalizacyjny: Warszawa, 2020; ISBN 978-83-8204-645-8.

10. PKN PN-EN ISO 527, Tworzywa Sztuczne -- Oznaczanie Właściwości Mechanicznych Przy Statycznym Rozciąganiu -- Część 1: Zasady Ogólne 2012.

11. ASM Handbook. Volume 19: Fatigue and Fracture; 4. print.; ASM International: Materials Park, Ohio, 2005; ISBN 978-0-87170385-9.

12. Mura, A.; Ricci, A.; Canavese, G. Investigation of Fatigue Behavior of ABS and PC-ABS Polymers at Different Temperatures. Materials 2018, 11, 1818, doi:10.3390/ma11101818. 
13. Mzabi, S.; Berghezan, D.; Roux, S.; Hild, F.; Creton, C. A Critical Local Energy Release Rate Criterion for Fatigue Fracture of Elastomers. J. Polym. Sci. B Polym. Phys. 2011, 49, 1518-1524, doi:10.1002/polb.22338.

14. Salopek Čubrić, I.; Čubrić, G.; Potočić Matković, V.M. Behavior of Polymer Materials Exposed to Aging in the Swimming Pool: Focus on Properties That Assure Comfort and Durability. Polymers 2021, 13, 2414, doi:10.3390/polym13152414.

15. Arnitel® EL550, TPC-ET - DSM Engineering Materials - Plastics Finder Available online: https://plasticsfinder.com/en/datasheet/Arnitel\%C2\%AE\%20EL550/zyp5G (accessed on 28 March 2021).

16. Queo ${ }^{\mathrm{TM}} 8230$ - Borealis Available online: https://www.borealisgroup.com/product/queo-8230 (accessed on 28 March 2021).

17. Courtney, T.H. Mechanical Behavior of Materials; McGraw Hill Education (India): New Delhi, 2013; ISBN 978-1-259-02751-2.

18. Topoliński, T. Analiza teoretyczna i badania kumulacji uszkodzeń zmęczeniowych konstrukcyjnych kompozytów polimerowych (Theoretical analysis and research on the accumulation of fatigue damage of structural polymer composites - in Polish); Wydawnictwa Uczelniane AT-R: Bydgoszcz, 1997;

19. Kancharala, A.; Philen, M. Enhanced Hydrodynamic Performance of Flexible Fins Using Macro Fiber Composite Actuators. Smart Materials and Structures 2014, 23, 115012, doi:10.1088/0964-1726/23/11/115012.

20. Pendergast, D.; Mollendorf, J.; Logue, C.; Samimy, S. Evaluation of Fins Used in Underwater Swimming. Undersea E hyperbaric medicine: journal of the Undersea and Hyperbaric Medical Society, Inc 2003, 30, 57-73.

21. Mars, W.V.; Fatemi, A. Factors That Affect the Fatigue Life of Rubber: A Literature Survey. Rubber Chemistry and Technology 2004, 77, 391-412, doi:10.5254/1.3547831. 